Article

\title{
Experimental evaluation of hydraulic resistance of pipelines from modern polymer materials
}

by Paliivets Maksim 1,*,

${ }^{1}$ Department of Computer Aided Design Systems and Engineering Calculations, Russian State Agrarian University - Moscow Timiryazev Agricultural Academy, Moscow 127434, Russia; paliivets@rgau-msha.ru

*Correspondence: maxim6663@mail.ru

Abstract: The aim of the studies was to test the hydraulic pressure losses along the length, local pressure losses, absolute and relative roughness values of the pipeline walls made of modern polymer material.

The article presents the results of the experimental studies of hydraulic resistance of pipelines from modern polymer materials, the method of theoretical determination of resistance coefficients in the VALTEC ISO 21003 metal polymer pipeline, the classification and method of determining the values of local hydraulic resistance coefficients of T-Junctions are given, the dependence for determining the Darcy $\lambda$ hydraulic friction coefficient associated with the value of the equivalent hydraulic roughness coefficient of the inner surface of pipes and the Reynolds number.

The experimental data of the hydraulic coefficient of friction Darcy $\lambda$ was compared with the known theoretical relationships of A.D. Altschul, Colbrooke for smooth pipes, Colbrooke and White, an alternative to the Colbrooke-White, Offengenden equation for low-shear pipes and pipes from polymer materials with Reynolds numbers $\operatorname{Re}>10^{4}$. Dependence of hydraulic coefficient of friction on relative equivalent roughness of pipeline walls and Reynolds number, specific energy loss per one linear meter on total flow rate in system of hydraulically short pipeline is obtained.

The empirical dependence of values of coefficients of local resistance $\zeta=\mathrm{f}(\mathrm{Q} 2 / \mathrm{Q} 3)$ from a ratio of the divided expenses of $\mathrm{Q} 2 / \mathrm{Q} 3$ of the equal-pass $\mathrm{T}$ Junction $\alpha=90^{\circ}$ the pipeline to a branch up, on pass in the direct T-Junction and division of streams at various internal pipeline diameters of VALTEC.

Keywords: pressure loss along length, Darcy hydraulic friction coefficient, local pressure loss in T-Junction, hydraulically short pressure pipeline, local resistance coefficient, flow rate, Reynolds number, flow rate, absolute and relative roughness of pipeline walls, turbulent flow mode. 


\section{Introduction}

When designing and hydraulic calculation of pipelines from modern polymer materials, two types of head losses are taken into account:

- pressure losses along the length (water friction against pipeline walls);

- local head losses (overcoming resistance in pipeline fittings: in shaped parts and pipe elements, in confusers and diffusers, in taps, turns and T-Junctions (when mixing and separating flows), in check valves, ball valves, valves and other elements.

The total hydraulic losses are expressed by the algebraic sum of the above head losses. Friction losses are determined by theoretical formulas or as a result of experimental studies. Local head losses are determined by reference or experimental data for a particular local resistance. Hydraulic calculation of pipelines from polymer materials requires taking into account a large number of a number of placed elements in the pipe fittings, which cause the occurrence of total local resistances. The kinematic structure of the flow behind these local resistances is complex, which means that in calculations the use of reference data is not always possible and correct.

In hydraulically short pipelines, quantitative head losses in local resistances can be $10 \div 15 \%$ from the total head losses.

The ubiquitous use of composite materials and new pipe manufacturing technologies contribute to the widespread use of polymer pipes. Reduction of total head losses along with accurate determination of their values is an urgent problem during transportation of liquids by pipelines. In the hydraulic calculation of pipelines of water, gas and heat supply systems made of polymer and metalpolymer pipes, it is necessary to determine the value of friction losses and local head losses.

The current state of the problem. The study of hydraulic resistances of polypropylene pipes and fittings is devoted to the work of I.Cisowska, A.Kotowski [1], experimental tests of head losses in plastic fittings, article T. Siwiec, D. Morawski, G. Karaban [2], analysis of formulas for calculating head losses by 
length in article S.E.Kutukova [3], investigation of water supply pipeline head losses during operation by A. Lal, D. Morawski, M. Chalecki [4] and others [2630].

The determination of head losses along the length is based on such a parameter as the Darcy coefficient $\lambda$ determined by the Darcy-Weisbach equation [5] and dependent on the value of the coefficient of equivalent hydraulic roughness of the inner surface of pipes $\Delta_{9}=\mathrm{k}_{\mathrm{e}}$ and the Reynolds number. The value of equivalent hydraulic roughness $\Delta_{9}=\mathrm{k}_{\mathrm{e}}$ can only be determined experimentally [6]. It is not allowed to use in calculations the absolute roughness of pipes measured by a profilometer, which is usually given in the manufacturer's certificate [7].

Friction resistance coefficients of polymer (plastic) pipes can be determined by formulas proposed by J.S. Offengenden [10]. In most cases, plastic pipes are small-haired $\left(\Delta_{3}=\mathrm{k}_{\mathrm{e}}<0.03 \mathrm{~mm}\right)$. The smallest absolute roughness is fluoroplastic pipes, the largest is fiberglass and phaolite pipes. In plastic pipes, micro- and macrovolarity is observed due to the technology of their manufacture. In the first approximation with Reynolds numbers $5 \cdot 10^{4}<\operatorname{Re}<3 \cdot 10^{5}$ (with an error of up to $25 \%$ or more) for hydraulic calculation of plastic pipes it is possible to use the formula Colbrooke [8], Colbrooke-White [3] or alternative to the equation Colbrooke-White [9] with substitution of values of $\Delta_{3}=k_{e}$ given in tables of reference for calculations of hydraulic and ventilation systems [10]. For polyethylene (unstabilized), fluoroplastic and polypropylene pipes the value of $\Delta_{\ni}$ is not determined, since for them the coefficient $\lambda$ can be found by formulas for smooth pipes [10].

Tables of reference book [10] show data on the value of equivalent surface roughness for polyethylene pipes equal to $\Delta_{3}=\mathrm{k}_{\mathrm{e}}=0,007 \mathrm{~mm}$ (multilayer pipes for water supply and heating systems with internal polyethylene layer). The sources $[10,11,12]$ give recommendations on the selection of equivalent roughness of the inner surface of pipes made of polymer materials with roughness values of $\Delta \ni=\mathrm{ke}$

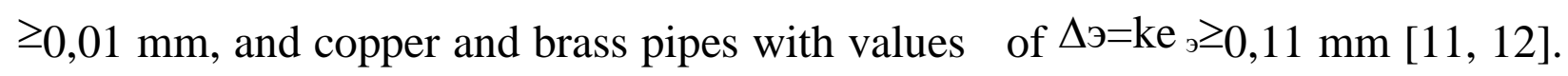


In the reference literature for plastic pipes (polyethylene, vinyl plastic), it is recommended to take equivalent roughness values equal to the values for allstretched pipes made of brass, copper or lead (technically smooth) - $\Delta \ni=\mathrm{ke}$ $=0,0015 \div 0,0005 \mathrm{~mm}$, polyethylene pipes $(2-20 \mathrm{~mm}) \Delta=0,003 \mathrm{~mm}$ [10]. According to manual [7], the equivalent roughness of the metal polymer pipeline is -, which makes them comparable in smoothness with new copper and glass pipes [7]. At the same time, it is indicated that the roughness of steel and copper pipes increases during operation, and in metal-plastic pipes this indicator remains unchanged for the entire service period [7].

In a pressure head turbulent stream for Reynolds numbers $R e=10^{4} \div 10^{5}$ values of coefficients of local resistance $\zeta$ depend generally on geometrical characteristics of a stream, Reynolds number practically doesn't affect values of these coefficients. According to the recommendations of A.D. Altschul for local pipeline resistances in which flow narrows, with its subsequent expansion, the auto-model zone begins with Reynolds numbers $R e>10^{4}$ [14], therefore, in copyright studies of losses on local resistances, auto-model by Reynolds number took more $10^{4}$. Therefore, in the hydraulic calculation of the metal polymer pipeline and its design, it is required to use the values of experimental coefficients of local head loss and length to accurately account for losses, which is an urgent task.

In T-Junctions of pipelines various scientists researched resistance: in Russia the T-Junctions were investigated by A.D. Altshul, P.N. Kamenev, V.N. Taliyev, S.I. Levin, A.M. Kurganov, P.G. Kiselyov and V.I. Kalitsun, M.M. Andriyashev, as well as. E. Idelchik [10.15]. There are not many new publications in the technical literature on the experimental determination of hydraulic losses during the flow of Newtonian liquids [16-19]. Currently, researchers are most often engaged in mathematical modeling of current structures using numerical models [20-24]. There are a large number of experiments to determine the coefficients of local resistance in various types of transfer and prefabricated T-Junctions, which 
were performed by V.P. Zubov, G. Vogel, E. Kinne, F. Peterman, A. Gardel, J. Štigler [32], N.P. Costa [33], A. Li [34], F. Koka [35], and also in polypropylene T-Junctions with defects was conducted by a team of researchers M. Kalenik, M. Chalecki, P. Wichowski [36, 37]. The design of the T-Junctions is very diverse, the studies were carried out as a result of the selection and comparison of the resistance coefficients of the T-Junctions based on the classification below (Fig. 1). 


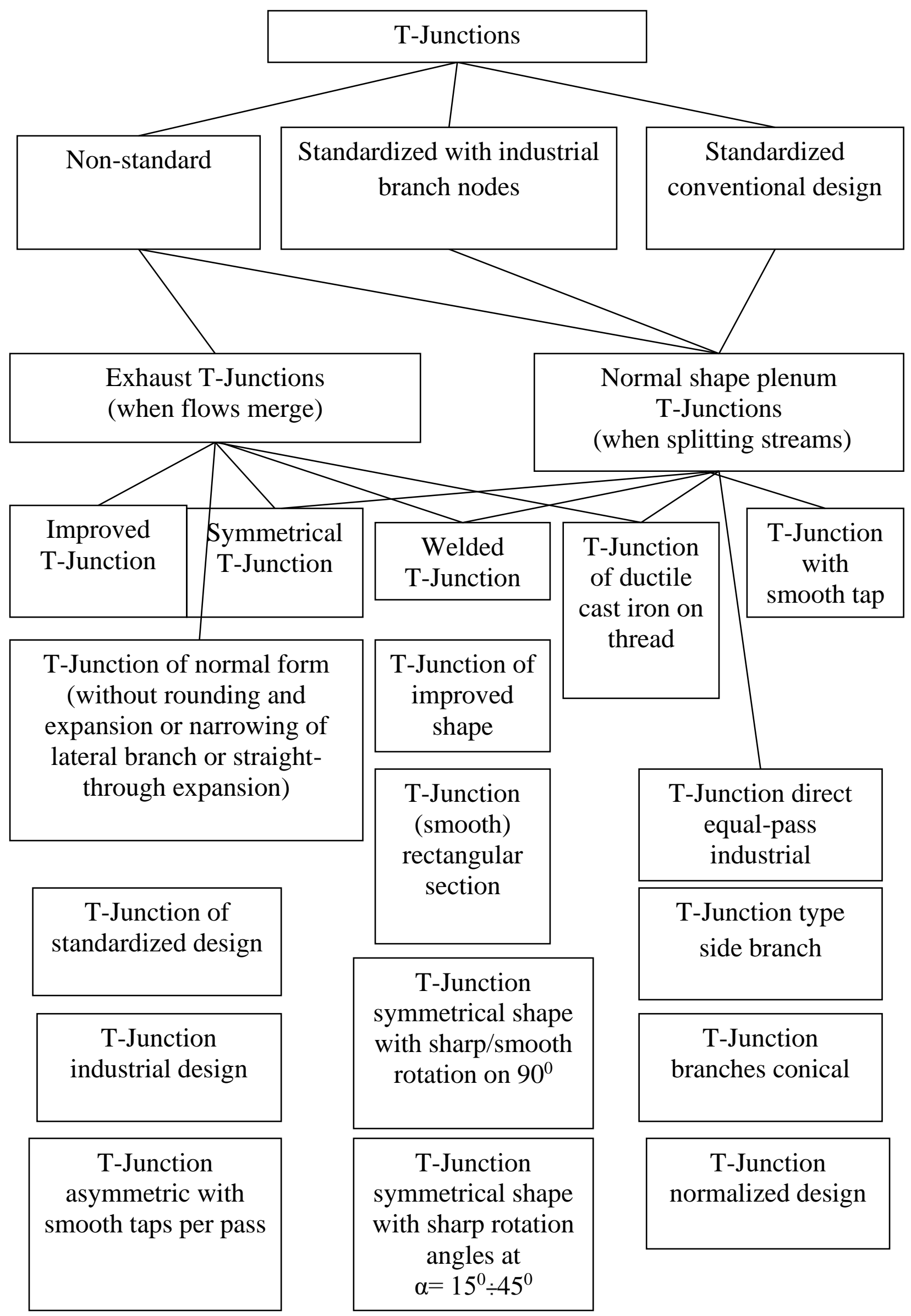

Figure 1. Types of T-Junctions. 
In Russia, approximate methods of theoretical determination of local resistance of T-Junctions used in water supply and ventilation are used, developed by P.N. Kamenev, S.R. Levin, N.N. Verevkin, I.E. Idelchik [15]. When calculating values from these formulas, values close to the values of these coefficients determined experimentally are obtained.

Correction coefficients are used in formulas to connect theoretical values of coefficients of local resistances and experimental resistances. As a result, the theoretical determination of the local resistance coefficients of the T-Junctions is the task of determining the values of these correction coefficients. Analytically, the values of the correction factors are not determined, they are obtained only for individual specific T-Junctions by comparing theoretical data and experimental ones.

When considering approximate methods for calculating local resistance of TJunctions, the Bernoulli equations and the number of motion are used. Therefore, the calculation formulas are quite similar to each other, and therefore the accuracy of the results obtained by various methods is almost the same. However, the difference in the methods of approach to determining resistances is different: the method of applying losses is used or the method is used without taking into account the overlap of losses in the T-Junction as a whole.

Due to the specifics of the studies, we will consider in more detail only asymmetric T-Junctions (plenum) with an angle $\alpha=90^{\circ}$, provided that the area of the side supply, direct passage and the prefabricated sleeve is equal $F_{\sigma}=F_{n}=F_{c}$.

Data of experiments of V.A. Zyuban in the standardized T-Junctions of pipelines of ship cooling systems showed that the value of coefficient of resistance $\zeta$ T-Junctions practically doesn't depend on Reynolds number, and depends generally on a ratio of expenses and a design of the T-Junction, however in work [35] it was succeeded to determine dependences $\zeta=\mathrm{f}(\mathrm{Re})$. 
Resistance coefficients of a T-Junction (supply) of the type $F_{\sigma}+F_{n}>F_{c}$, $F_{n}=F_{c}$ of ductile cast iron on thread $\alpha=90^{\circ}$ are determined by formulas [10]:

Lateral branch:

$$
\zeta_{c . \sigma}=\frac{\Delta p_{\sigma}}{\rho w_{c}^{2} / 2}
$$

see table and curves $\zeta_{c .6}=f\left(\frac{Q_{\sigma}}{Q_{c}}\right)$ with different $\frac{F_{\sigma}}{F_{n}}[10]$.

$$
\zeta_{\sigma}=\frac{\Delta p_{\sigma}}{\rho w_{\sigma}^{2} / 2}=\frac{\zeta_{c . \bar{\sigma}}}{\left(\frac{Q_{\sigma}}{Q_{c}} \frac{F_{c}}{F_{\sigma}}\right)^{2}},
$$

Straight pass:

$$
\zeta_{c . n}=\frac{\Delta p_{n}}{\rho w_{c}^{2} / 2}
$$

see table and curves $\zeta_{c . n}=f\left(\frac{Q_{n}}{Q_{c}}\right)$ with different $\frac{F_{\sigma}}{F_{c}}[10]$.

$$
\zeta_{n}=\frac{\Delta p_{n}}{\rho w_{n}^{2} / 2}=\frac{\zeta_{c . n}}{\left(1-\frac{Q_{\sigma}}{Q_{c}}\right)^{2}},
$$

For T-Junctions of type $F_{\sigma}+F_{n}>F_{c}, F_{n}=F_{c}$ value $A^{\prime}$ see table 1.54 [10], and $K_{\sigma}^{\prime}$ is taken to be zero..

For T-Junctions of type $F_{\sigma}+F_{n}=F_{c}$ value $A^{\prime}=1,0$, and $K_{\sigma}^{\prime}$ see table 1.55 [10].

Straight pass:

For T-Junctions of type $F_{\sigma}+F_{n}>F_{c}, F_{n}=F_{c}$ (in limits $\frac{w_{n}}{w_{c}} \leq 1,0$ )

$$
\zeta_{c . n} \equiv \frac{\Delta p_{n}}{\rho w_{c}{ }^{2} / 2}=\tau_{n}\left(\frac{Q_{\sigma}}{Q_{c}}\right)^{2}
$$

where $\tau_{n}$ - reference data [10]. 


\section{Materials and Methods}

Experimental metal polymer pipeline VALTEC ISO 21003 was installed in the hydraulics laboratory RSAU-Moscow Timiryazev Agricultural Academy (Fig.2), the pipeline was fixed with plastic ties to the base. The material and diameter of the pipeline was chosen due to its resistance to salt deposits and fouling with iron oxide during operation, as presented in work [4], as well as widespread use in water supply, heating, soil heating systems, as part of pipelines pumping non-aggressive liquids. Process pipeline consists of internal and external layers of crosslinked polyethylene PEX, between which there is a layer of aluminum foil and a layer of adhesive based on polyethylene.

Through the inlet pipe of the self-sucking pump Pedrollo JSWm 1SKh ejector type and then through the outlet pipe, water entered the pipeline, which was located along the laboratory next to the hydrometric tray. The individual sections of the pipeline were combined by means of connecting fittings, the sections of the metal polymer pipe were placed after a predetermined distance between the fittings, which was selected taking into account the lengths of the influence of the resistances, and laid along the entire length equal to $l=625 d=10 \mathrm{~m}$.

Instrumentation was arranged taking into account the lengths of resistance downstream of the pipeline and taking into account the characteristics of the instrument. The pipeline accommodated VIEIR pressure gauges to record pressure losses. The water flow rate was measured at the end of the experimental pipeline according to two small sensors TS-2 the Streamlux SLS-700P portable ultrasonic meter meter, the readings of which were recorded after some time of operation of the pump. 


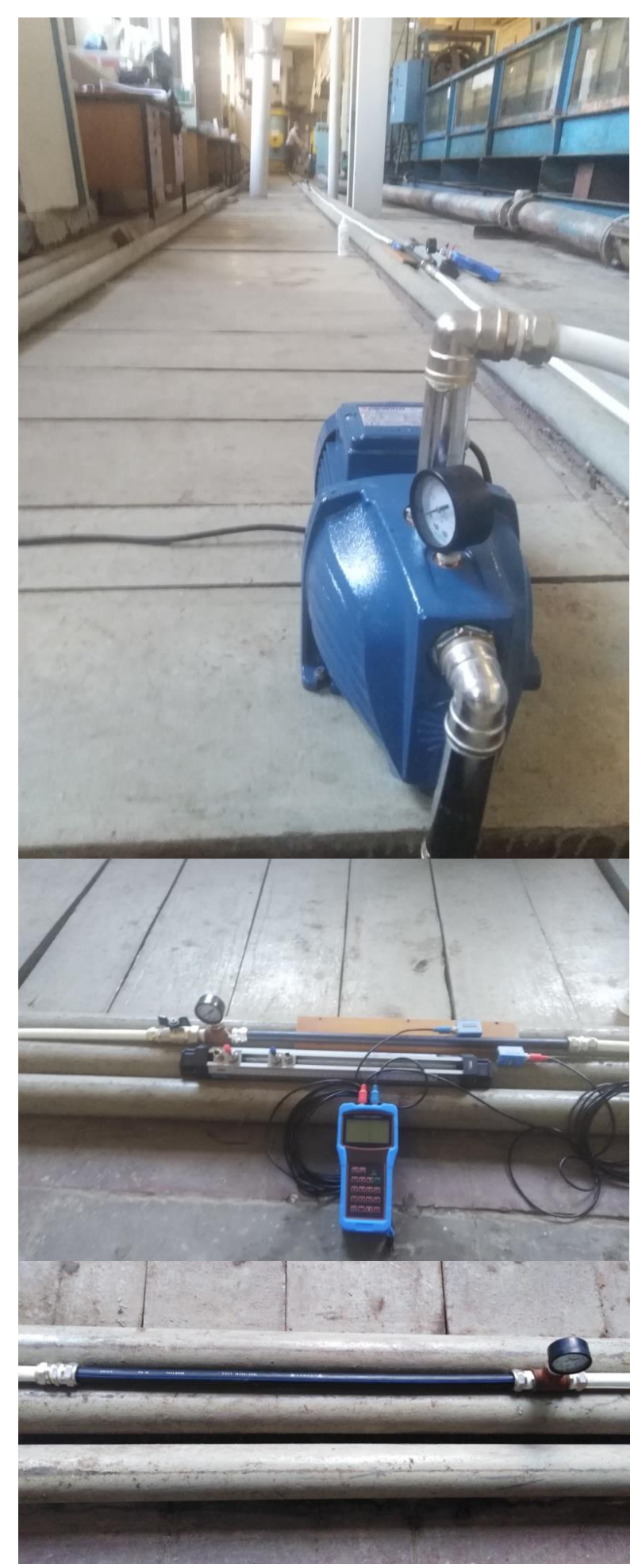

Figure 2. Pilot pipeline.

Research material. Pilot hydraulic testing of VALTEC PexbAL0,3-Pexb metal polymer pipeline.

Since the pressure flow entered the pipeline through the nozzle and the pump elbow, it was therefore necessary to determine the length of the initial section. The length of the initial section (stabilization) in the pipeline after the 
pump outlet nozzle in experiments was $-l=93,75 \cdot d=93,75 \cdot 0,016=1,5 m$, which is more than the values of theoretical calculations according to the formulas of V.S. Borovkov and F.G. Mayranovsky, E.A. Gizh.

Length of stabilization $l$ section is determined by formula:

$$
l=0,693 \cdot d \cdot \operatorname{Re}^{1 / 4},
$$

For turbulent motion, the initial length of the section for all regions of resistance can be determined by the formula of V.S. Borovkov and F.G. Mayranovsky [13]:

$$
l=d \cdot \frac{0,52}{\lambda},
$$

According to the formula E.A. Gizh, the length of the initial section in the pipes during turbulent mode depends on $d$, coefficient $\lambda$ and is taken into account by the formula:

$$
l=d \cdot(0,45 / \lambda+8,7),
$$

where $\lambda$ - is the Darcy coefficient in a uniform flow.

Since the hydraulic coefficient of friction in the experiments took values from $\lambda=0,02052$ to 0,02910 and changed within the Reynolds numbers $\operatorname{Re}=1,0 \cdot 10^{4} \div 8,0 \cdot 10^{4}$ then $l$ the formulae (6), (7) and (8) will be equal:

$$
\begin{gathered}
l=0,693 \cdot 0,016 \cdot\left((1,0 \div 8,0) \cdot 10^{4}\right)^{1 / 4}=(0,11088 \div 0,1864) \mathrm{m}, \\
\quad l=0,016 \cdot \frac{0,52}{(0,02052 \div 0,02910)}=(0,2859 \div 0,4054) \mathrm{m}, \\
l=0,016 \cdot\left(\frac{0,45}{(0,02052 \div 0,02910)}+8,7\right)=(0,39 \div 0,49) \mathrm{m} .
\end{gathered}
$$

Prior to starting and fixing measurements, the pump of the experimental plant was operated for a period of time to ensure a steady (stabilized) flow pattern of the pressure flow. Between the measurements, the duration of the experimental plant was about 15-30 minutes before the start of steady flow, after which it was possible to start recording the readings of measuring gauges and a meter. 
Procedure for calculation of experimental data:

In the pressure tube with diameter $\mathrm{d}$ and flow rate $\mathrm{Q}$, the cross-sectional area $\omega$ and the flow rate of water $\mathrm{V}$ were determined:

$$
\begin{gathered}
\omega=\frac{\pi d^{2}}{4}, \\
V=\frac{Q}{\omega} .
\end{gathered}
$$

In each series of experiments, the water temperature of the hydrometric tray was measured with a thermometer. By measurements, the kinematic viscosity coefficient of water and the Reynolds number were determined:

$$
\operatorname{Re}=\frac{V d}{v},
$$

where $V-$ is the average flow rate, $\mathrm{m} / \mathrm{s} ; d$ - pipe diameter, $\mathrm{m} ; \omega-$ the area of live section of a pipe, $\mathrm{m}^{2} ; Q$ - water flow rate, $\mathrm{m}^{3} / \mathrm{s} ; v$ - coefficient of kinematic viscosity, $\mathrm{m}^{2} / \mathrm{s}\left(\mathrm{t}^{0}=14^{0} \div 15^{0} \mathrm{C}\right)$.

According to the Darcy-Weisbach equation [5], friction losses were calculated:

$$
h_{\omega_{1-2}}=h_{l}=\lambda \frac{l}{d} \frac{V^{2}}{2 g},
$$

where $V-$ is the average flow rate, $\mathrm{m} / \mathrm{s} ; d-$ pipe diameter, $\mathrm{m}$; $h_{\omega_{1-2}}=h_{l}=\frac{p_{1}}{\rho g}-\frac{p_{2}}{\rho g}-$ friction head loss, $\mathrm{m} ; l-$ length of pipe section between pressure gauge readings $(l=403 d) ; g-$ free fall acceleration, $\mathrm{m} / \mathrm{s}^{2}$.

By practical consideration the coefficient of local losses of a pressure $\zeta$ was defined on length of the site of the pressure head pipeline with zones of influence of local resistance (fig. 3) up and downstream. Head loss in T-Junction was calculated by formula [13]:

$$
h_{M}=\zeta \frac{V^{2}}{2 g}
$$


where $V$ - average flow velocity, $\mathrm{m} / \mathrm{s} ; h_{\mu}=\frac{p_{1}}{\rho g}-\frac{p_{2}}{\rho g}-$ local head loss (upstream and downstream in resistance influence zone, $\mathrm{m}$ ), $g$ - free fall acceleration, $\mathrm{m} / \mathrm{s}^{2}$.
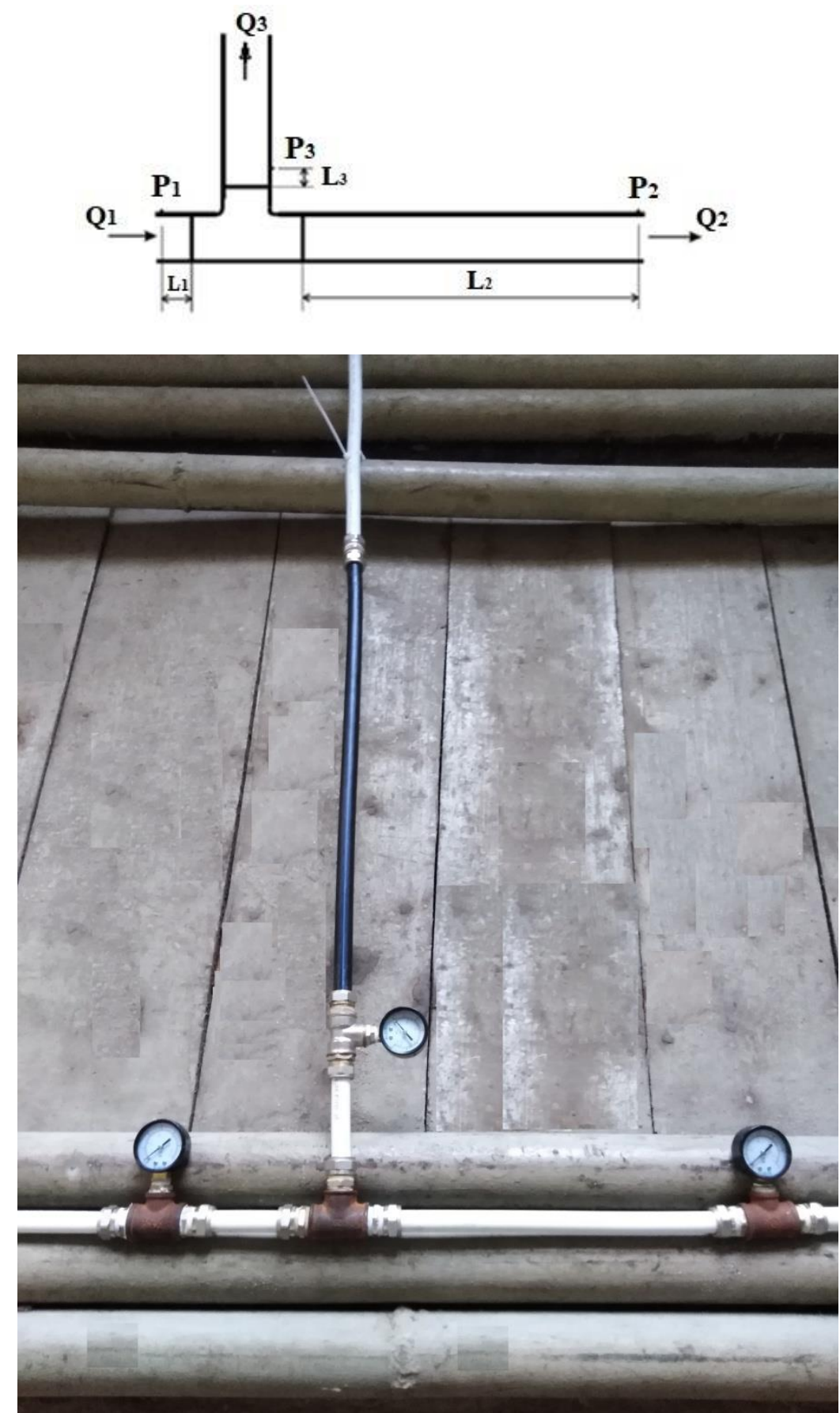

Figure 3. Determination of local head loss in equal-pass T-Junction at flow division at angle $\alpha=90^{\circ}$.

\section{Results and Discussion}

In the results of experimental studies at different liquid flow rates in the pipeline and the average flow rate, the statistical dependence of the hydraulic 
coefficient of friction on the dimensionless Reynolds number in the $R e=$ $1 \cdot 10^{4} \div 8 \cdot 10^{4}$ interval was obtained and interpreted (Figure 4 ).

$$
\lambda=\mathbf{f}(\mathbf{R e}) \text { in VALTEC pipeline }
$$

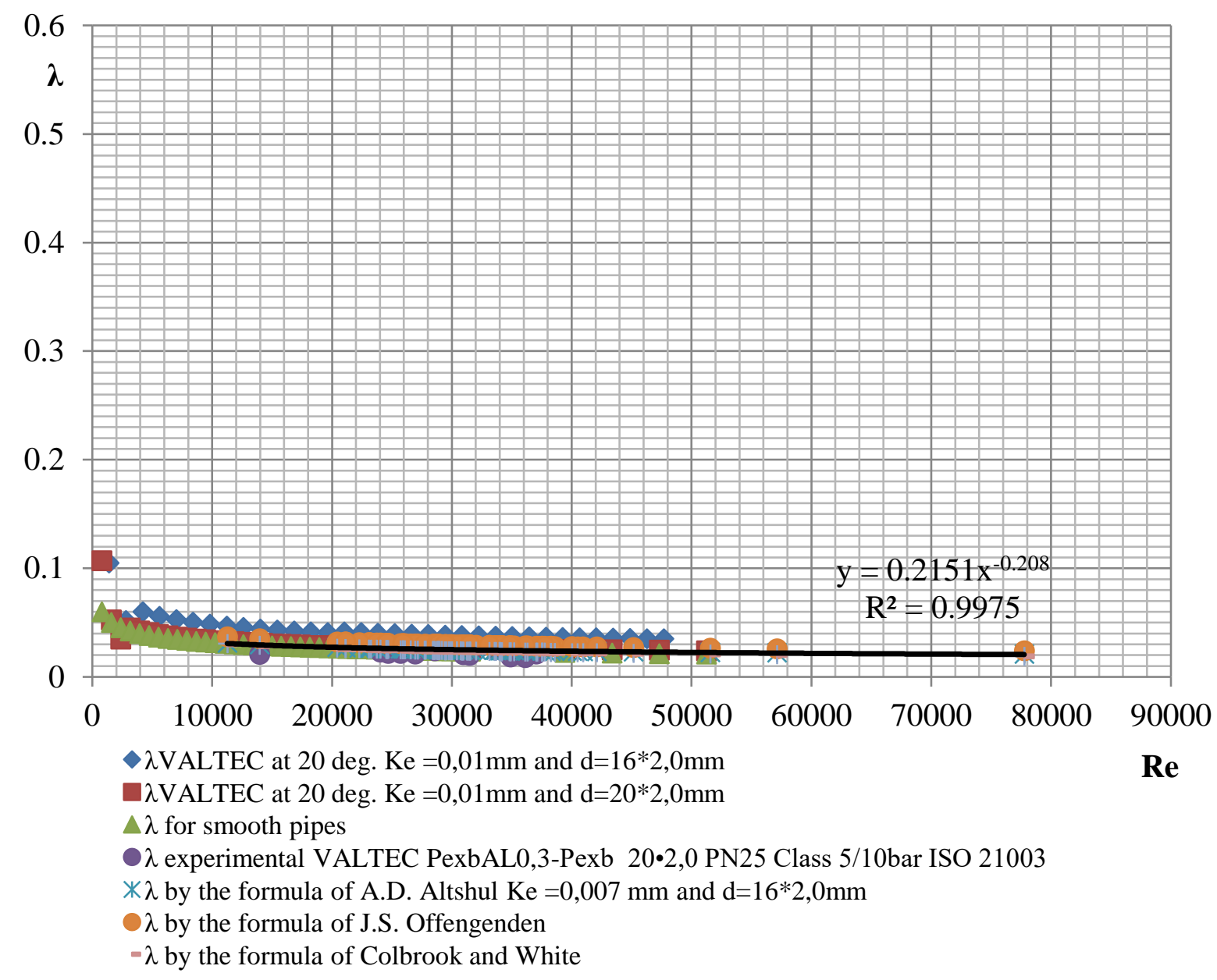

Figure 4. Dependence of hydraulic friction coefficients $\lambda=f(R e)$.

Figure 4 shows the experimentally obtained points and values $\lambda=f\left(\operatorname{Re} ; \frac{\Delta_{\ni}}{d}\right)$ of the hydraulic coefficient of friction calculated according to the formulas of A.D. Altschul [14], Colbrooke [6.8], Colbrooke-White [3] or alternatives to the Colbrooke-White equation [9] and J.S. Offengenden [10].

In the range of Reynolds numbers in question, the most accurate coincidence of experimental and theoretical values was obtained using the formula A. D. Altschul. Theoretical values $\lambda=f\left(R e ; \frac{\Delta_{\ni}}{d}\right)$ calculated for the pipeline with relative roughness $\Delta=\frac{\Delta_{9}}{\mathrm{~d}}=0,000583, \Delta=\frac{\Delta_{9}}{\mathrm{~d}}=0,000438$ and absolute equivalent roughness $\Delta_{\ni}=k_{e}=0,007 \mathrm{~mm}$ have the smallest discrepancy with experimental 
points. Theoretical calculation for polymer pipelines can be made according to formulas of other researchers $[26,27,28,29,30]$ using obtained values of absolute and relative roughness of pipeline walls.

The error of hydraulic measurements was calculated according to GOST R ISO [25]. The main hydraulic parameters defined in the experiment - hydraulic coefficient of friction $\lambda$ and coefficient of local resistances $\zeta$, which are calculated indirectly and require careful determination of errors of experimental data. Formulas for determining the values of $\lambda$ and $\zeta$ :

$$
\begin{aligned}
& \lambda=2 g \cdot \frac{\pi^{2}}{16} \cdot d^{5} \cdot h_{l} \cdot l^{-1} \cdot Q^{-2}, \\
& \zeta=g \cdot \frac{\pi^{2}}{2} \cdot d^{4} \cdot h_{m} \cdot Q^{-2},
\end{aligned}
$$

Systematic and random errors of the experimental value of the hydraulic friction coefficient] and the coefficient of local resistances were calculated in the work. In the formula for calculating the bias of the Darcy coefficient, the parameters measured in the experience were substituted:

$$
B_{\lambda}= \pm \lambda \cdot\left(5 \cdot \frac{B_{d}}{d}+\frac{B_{h_{l}}}{h_{l}}+(-1) \cdot \frac{B_{l}}{l}+(-2) \cdot \frac{B_{Q}}{Q}\right),
$$

The random component of the Darcy coefficient error was calculated by the formula:

$$
e_{\lambda}= \pm \lambda \cdot \sqrt{5^{2} \cdot\left(\frac{e_{d}}{d}\right)^{2}+\left(\frac{e_{h_{l}}}{h_{l}}\right)^{2}+(-1)^{2} \cdot\left(\frac{e_{l}}{l}\right)^{2}+(-2)^{2} \cdot\left(\frac{e_{Q}}{Q}\right)^{2}},
$$

The total relative error of determining the Darcy coefficient was calculated using the formula:

$$
e= \pm \frac{\sqrt{B_{\lambda}^{2}+e_{\lambda}^{2}}}{\lambda} \cdot 100 \%
$$

and with a confidence probability of $95 \%$ was $\pm 4,05 \%$. 
Systematic error of experimental value of local resistance coefficient:

$$
B_{\zeta}= \pm \zeta \cdot\left(4 \cdot \frac{B_{d}}{d}+\frac{B_{h_{\mu}}}{h_{\mu}}+(-2) \cdot \frac{B_{Q}}{Q}\right),
$$

The random error component of the local resistance coefficient was calculated using the formula:

$$
e_{\zeta}= \pm \zeta \cdot \sqrt{4^{2} \cdot\left(\frac{e_{d}}{d}\right)^{2}+\left(\frac{e_{h_{u}}}{h_{M}}\right)^{2}+(-2)^{2} \cdot\left(\frac{e_{Q}}{Q}\right)^{2}},
$$

The total relative error of determining the coefficient of local resistances was calculated using the formula:

$$
e= \pm \frac{\sqrt{B_{\zeta}^{2}+e_{\zeta}^{2}}}{\zeta} \cdot 100 \%
$$

and with a confidence probability of $95 \%$ was $\pm 3 \%$.

As in article [4], based on experimental data, reliable statistical dependencies of specific energy loss on consumption are obtained (Fig. 5).

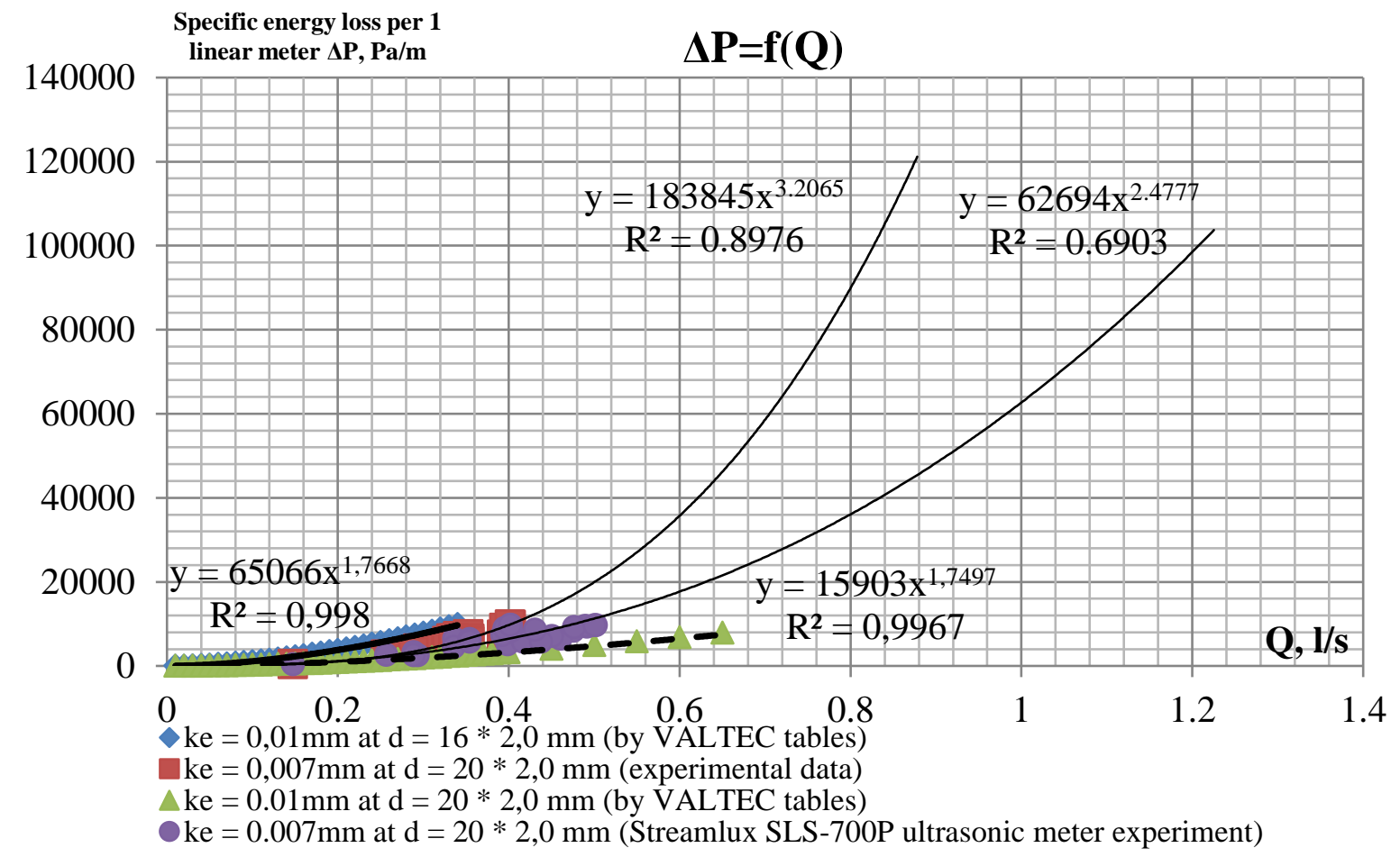

Figure 5. Dependencies of specific energy loss $\Delta \mathrm{P}, \mathrm{Pa} / \mathrm{m}$ per 1 linear meter of pipeline on flow rate $\mathrm{Q}, 1 / \mathrm{s}$. 
Figures 6-7 show experimentally detected statistically reliable dependencies of local resistance coefficients of T-Junctions in VALTEC pipeline with diameter $\varnothing 16 \mathrm{~mm}$ and $\varnothing 20 \mathrm{~mm}$ at flow division at angle $\alpha=90^{\circ}$ at Reynolds numbers $\operatorname{Re}>10^{4}$.

The author's experimental data (Fig. 6-7) on the coefficients of local resistance of T-Junctions are obtained depending on the ratio of Q2/Q3 costs and the constant design of T-Junctions, unlike the studies of the team of authors M. Kalenik, M. Chalecki, P. Wichowski [35-37], which obtained local resistance coefficients in welded polypropylene T-Junctions with a diameter of $13.2 \mathrm{~mm}$ with various defects, resulting from the pressing of welded elements (fittings) against each other. Author resistance values and data [35-38] obtained depending on Reynolds numbers in the interval $\operatorname{Re}=1 \cdot 10^{4} \div 3,2 \cdot 10^{4}$ are higher than the data values of D.C.Rennels, H.M. Hudson [39] used for designing water supply engineering systems.

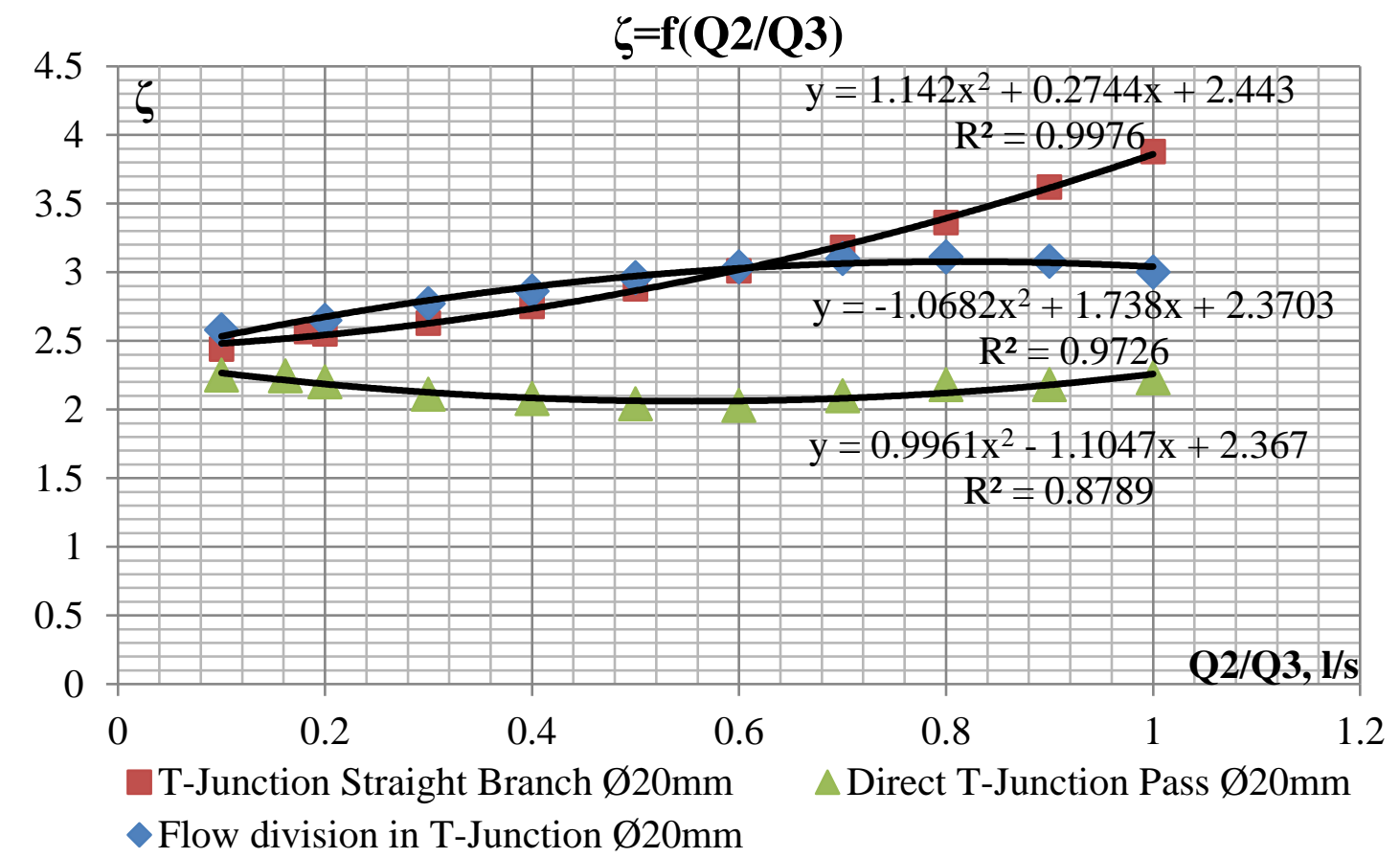

Figure 6. Dependences $\zeta=\mathrm{f}(\mathrm{Q} 2 / \mathrm{Q} 3)$ of coefficients of local resistance of the direct equal-pass T-Junction in the VALTEC PexbAL0.3-Pexb Ø16mm pipeline at division of streams at an angle $\alpha=90^{\circ}$ at $\operatorname{Re}>10^{4}$. 


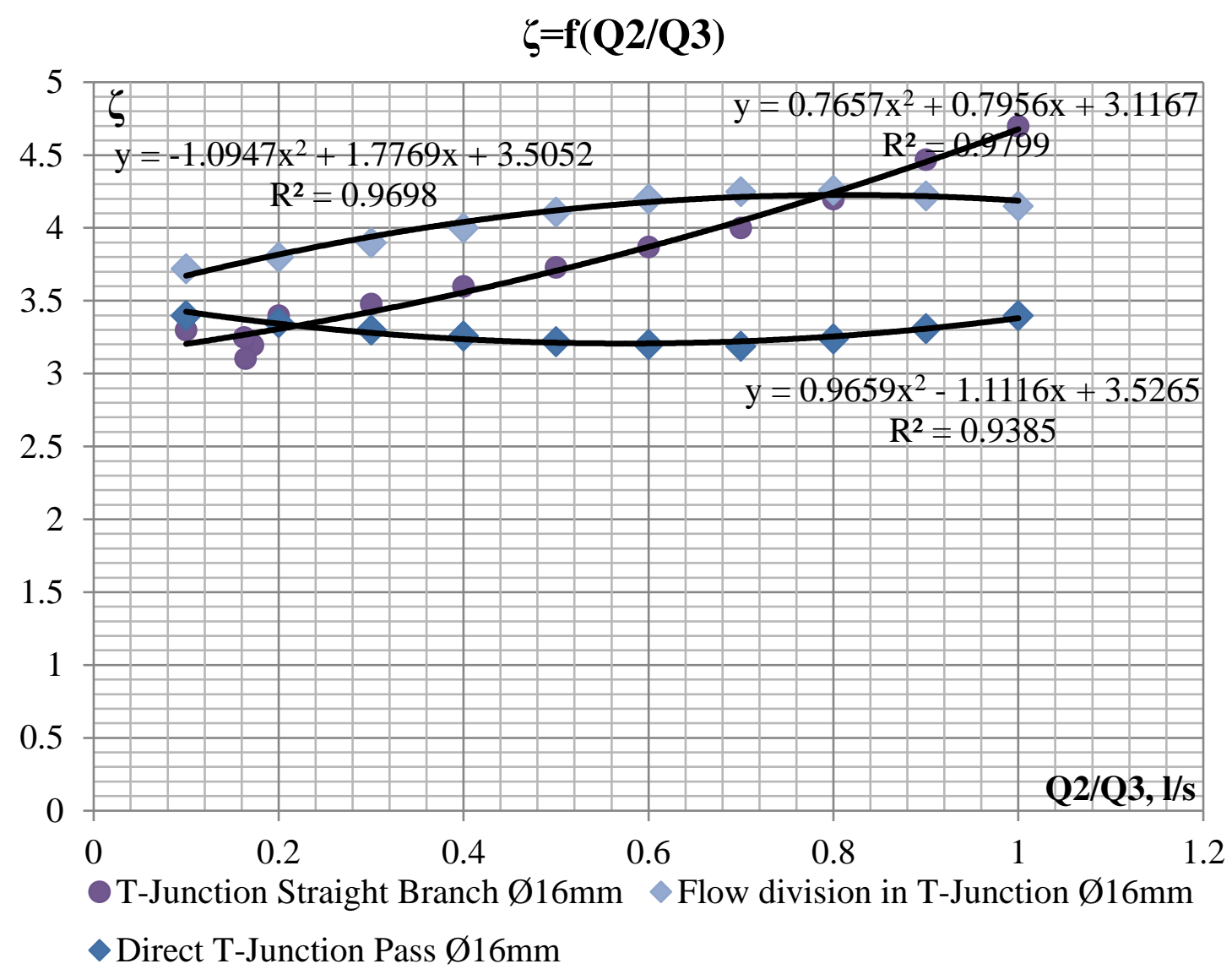

Figure 7. Dependences $\zeta=\mathrm{f}(\mathrm{Q} 2 / \mathrm{Q} 3)$ of coefficients of local resistance of the direct equal-pass T-Junction in the VALTEC PexbAL0.3-Pexb Ø20 $\mathrm{mm}$ pipeline at division of streams at an angle $\alpha=90^{0}$ at $\operatorname{Re}>10^{4}$.

The results of accuracy of hydraulic experiments were established according to the requirements of GOST R ISO [25]. Experimental studies were carried out under conditions of repeatability and reproducibility. Since the systematic and random components of the error of determining resistance coefficients were comparable, the total relative errors of the Darcy coefficient and local resistances were calculated, which amounted to $\pm 4.05 \%$ and $\pm 3 \%$, respectively (for a confidence probability of $95 \%$ ).

\section{Conclusions}

Based on the performed experiments, head losses along the length in the VALTEC metal polymer pipeline were investigated and the statistical dependence of the hydraulic coefficient of friction on the relative equivalent roughness of the pipeline walls and the dimensionless Reynolds number in the number interval was obtained and interpreted $\operatorname{Re}=1 \cdot 10^{4} \div 8 \cdot 10^{4}$. Value of absolute equivalent and 
relative roughness of walls of VALTEC metal polymer pipeline is experimentally determined. Experimental data are consistent with theoretical values calculated using the formulas of A.D. Altschul, Colbrooke, Colbrooke and White, an alternative to the Colbrooke-White and J.S. Offengenden equations for pipelines from polymers at Reynolds numbers. For the first time, the value of hydraulically equivalent roughness of the material of the inner walls of the VALTEC ISO 21003 metal polymer pipeline was obtained experimentally.

Empirical dependences of values of coefficients of local resistance $\zeta=\mathrm{f}$ (Q2/Q3) in equal-pass T-Junctions $\alpha=90^{\circ}$ are also received at division of a stream of liquid depending on a ratio of expenses of Q2/Q3 in a branch up, on direct pass and division of streams for internal pipeline diameters of VALTEC $\varnothing 16 \mathrm{~mm}$ and $\emptyset 20 \mathrm{~mm}$ which will be coordinated with the known dependences presented in the section introduction.

Experimentally certain dependences and values of coefficients of local resistance of T-Junctions can be used at hydraulic calculation of local losses of a pressure of knots of resistance in a zone of their mutual influence at each other, at placement in a zone of influence of T-Junctions with local resistance such as: confusors and diffusers of a connecting fitting, ball valves, T-Junctions, non-return valves, gates, knee, branches. The obtained data will allow to calculate values of coefficients of mutual influence of local resistance units, as well as to perform optimal layout and arrangement of resistances at approach or their separation by the relative distance $l / d$, as well as to take into account values of coefficients of mutual influence in the zone of their intensive mutual influence when designing and hydraulic calculations of pipeline systems using metal-polymer pipeline and shaped parts of VALTEC valves.

\section{Author Contributions}

Validation, visualization, data curation, P.M.; writing-original draft preparation, P.M.; writing — review and editing, P.M.

\section{Funding}

This study received intra-university grant support for research projects 
within the framework of the academic strategic leadership program "Priority 2030" Russian State Agricultural University - Moscow Timiryazev Agricultural Academy.

\section{Data Availability Statement}

Data will be available on request.

\section{Acknowledgments}

The research was also supported by the Russian State Agricultural University - Moscow Timiryazev Agricultural Academy, Moscow.

\section{Conflicts of Interest}

The author declare no conflict of interest. The funders had no role in the design of the study; in the collection, analyses, or interpretation of data; in the writing of the manuscript, or in the decision to publish the results.

\section{References}

1. Cisowska, I., Kotowski, A. Studies of hydraulic resistance in polypropylene pipes and pipe fittings / I. Cisowska, A. Kotowski // Foundations of Civil and Environmental Engineering. - 2006. - №8. - P.37-57.

2. Siwiec, T., Morawski, D., Karaban, G. Experimental tests of head losses in welded plastic fittings / T. Siwiec, D. Morawski, G. Karaban// Gaz Woda Technika Sanitarna. - 2002. - 2. - P.49-68.

3. Kutukov, S. E. The establishment of pipeline hydraulics: retrospective of researches of hydraulic losses in pipes / S. E. Kutukov, A. I. Golianov, O. V. Chetvertkova // OIJ. - 2019. - Volume 2019, Issue 07. - P.128-133. - DOI 10.24887/0028-2448-2019-7-128-133.

4. Lal, A., Morawski, D., Chalecki, M. Hydraulic and Technological Investigations of a Phenomenon Responsible for Increase of Major Head Losses in Exploited Cast-Iron Water Supply Pipes / A. Lal, D. Morawski, M.Chalecki //. Water. - 2021. - 13. - P.1604. https://doi.org/10.3390/w13111604.

5. Brown, G. O. The history of the Darcy-Weisbach equation for pipe flow resistance / G. O. Brown // In Proceedings of the Environmental and Water 
Resources History. ASCE - American Society of Civil Engineers. - 2002. - pp. 34-43. https://doi.org/10.1061/40650(2003)4.

6. Brkić, D. Review of explicit approximations to the Colebrook relation for flow friction / D. Brkić // Journal of Petroleum Science and Engineering. 2011. - Vol. 77. No 1. - P. 34-48. - DOI 10.1016/j.petrol.2011.02.006. https://doi.org/10.1016/j.petrol.2011.02.006.

7. Afonin, A.N., Sushitsky, O.I. Manual for the design, installation and operation of cold, hot water supply and heating systems using TM VALTEC metal polymer pipes. Edited by Gorbunov V.I. / A.N. Afonin, O.I. Sushitsky. - M.: JSC "NIISantehniki," 2009. - 199 p.

8. Samadianfard, S. Gene expression programming analysis of implicit Colebrook-White equation in turbulent flow friction factor calculation / S. Samadianfard // Journal of Petroleum Science and Engineering. - 2012. - Volumes 92-93 - P.48-55.

9. Sonnad, J. R., \& Goudar, C. T. Turbulent Flow Friction Factor Calculation Using a Mathematically Exact Alternative to the Colebrook-White Equation / J. R. Sonnad\& C. T. Goudar // Journal of Hydraulic Engineering. 2006. - 132(8). - p. 863-867. https://doi.org/10.1061/(asce)07339429(2006)132:8(863).

10. Handbook on calculations of hydraulic and ventilation systems/I.G. Grachev, V.M. Nizovtsev, S.Yu. Pirogov, etc., ed. A.S. Yuryev. 3rd ed., Supplement and processing. St. Petersburg: NPO NPO Peace and Family, NPO Professional, 2006. - 1154 p., Il. ISBN 5-98371-011-7.

11. SP 399.1325800.2018. Design and installation of pipelines of water supply and sewerage systems from polymer materials. General requirements. Access mode: https://docs.cntd.ru/document/552304873.

12. SP 60.13330.2020. Heating, ventilation and air conditioning. Heating, ventilation and air conditioning. - Access mode: https://docs.cntd.ru/document/573697256. 
13. Shterenlicht, D.V. Hydraulika: textbook. 5th ed., Erased. - St. Petersburg: Publishing House "Lan," 2015. - 656 p.: il.

14. Altshul, A.D. Hydraulic resistances: textbook. 2nd ed., Redesign. and supplement. - M.: Nedra, 1982. - 224 s.

15. Handbook of Hydraulic Resistance, 3rd Edn. By I. E. Idelchik. Begell House, 1994. 790 pp. ISBN 0-8493-9908-4. £138.95 // Journal of Fluid Mechanics. - 1998. - Vol. 354. - P. 376-378.

16. Kalenik, M. Empirical Formulas for Calculation of Negative Pressure Difference in Vacuum Pipelines / M. Kalenik // Water. - 2015. - 7(10). - P.52845304.

17. Kalenik, M. Real Values of Local Resistance Coefficient During Flow of Water Through Welded Polypropylene Elbows / M. Kalenik // Ochr. Sr. 2019. - 41. - P.23-30.

18. Wichowski, P., Siwiec, T., Kalenik, M. Effect of the Concentration of Sand in a Mixture of Water and Sand Flowing through PP and PVC Elbows on the Minor Head Loss Coefficient / P. Wichowski, T. Siwiec, M. Kalenik // Water. 2019. - 11. - P.828.

19. Basset, M., Winterbone, D., Pearson, R. Calculation of steady flow pressure loss coefficients for pipe junctions / M. Basset, D. Winterbone, R. Pearson // Proceedings of the Institution of Mechanical Engineers, Part C: Journal of Mechanical Engineering Science. - 2001. - P.861-881.

20. Ono, A., Kimura, N., Kamide, H., Tobita, A. Influence of elbow curvature on flow structure at elbow outlet under high Reynolds number condition / A. Ono, N. Kimura, H. Kamide, A. Tobita // Nuclear Engineering and Design. 2011. - Volume 241, Issue 11. - P.4409-4419.

21. Csizmadia, P., H"os, C. CFD-based estimation and experiments on the loss coefficient for Bingham and power-law fluids through diffusers and elbows / P. Csizmadia, C. H"os // Computers \& Fluids. - 2014. - 99. - P.116123. 
22. Dutta, P., Nandi, N. Effect of Reynolds number and curvature ratio on single phase turbulent flow in pipe bends / P. Dutta, N. Nandi // Mechanics and Mechanical Engineering. - 2015. - 19(1). - P.5-16.

23. Dutta, P., Saha, S.K., Nandi, N., Pal, N. Numerical study on flow separation in $90^{\circ}$ pipe bend under high Reynolds number by k- $\varepsilon$ modeling / P. Dutta, S.K. Saha, N. Nandi, N. Pal // Engineering Science and Technology, an International Journal. - 2016. - 19. - P. 904-910.

24. Ligaj, K., Widomski, M. K., Musz-Pomorska, A. Minor pressure losses for different connections of PP-R and PEX/Al/PEX installation pipes // E3S Web of Conferences. - EDP Sciences, 2019. - T. 100. - C. 00045.

25. GOST R ISO 5725-6-2002. Accuracy (correctness and precision) of measurement methods and results. Use accuracy values in practice. Vved. 200204-23. - M.: Publishing House of Standards, 2002. - 43 s.

26. Genic S., Arandjelovic I., Kolendic P., Jsric M., Budimir N. A review of explicit approximations of Colebrook's equation / S. Genic, I. Arandjelovic, P. Kolendic, M. Jsric, N. Budimir // FME Transactions. - 2011. - Vol. 39, No 2. - P. $67-71$.

27. Brkic, D., Žarko, C. Evolutionary optimization of colebrook's turbulent flow friction approximations / D. Brkic, C. Z Z arko // Fluids. - 2017. 2(15). - P.1-27.

28. Oke, I.A., Stephen, O., Adeosun, O.O. Performance evaluation for Darcy friction factor formulae using Colebrook-white as reference / I.A. Oke, O. Stephen, O.O. Adeosun // Ife Journal of Science. - 2015. - Vol. 17, no. 1. - P.7586.

29. Zeghadnia, L., Robert, J. L. \& Achour, B. Explicit solutions for turbulent flow friction factor: A review, assessment and approaches classification / / L. Zeghadnia, J. L. Robert \& B. Achour / Ain Shams Engineering Journal. Ain Shams University. - 2019. - Volume 10, Issue 1. - P. 243-252. https://doi.org/10.1016/j.asej.2018.10.007. 
30. Madeira, A. A. Major and minor head losses in a hydraulic flow circuit: Experimental measurements and a Moody's diagram application / A. A. Madeira // Ecletica Quimica. - 2020. - 45(3). - P. 47-56. https://doi.org/10.26850/1678-4618eqj.v45.3.2020.

31. Štigler, J., Klas, R., Kotek, M., Kopecký, V. The fluid flow in the Tjunction. The comparison of the numerical modeling and PIV measurement / J. Štigler, R. Klas, M. Kotek, V. Kopecký // Procedia Engineering. - 2012. - 39. - P. 19-27. https://doi.org/10.1016/j.proeng.2012.07.003.

32. Costa, N.P., Maia, R., Proença, M.F., Pinho, F.T. Edge effects on the flow characteristics in a $90 \mathrm{deg}$ Tee junction / N.P. Costa, R. Maia, M.F. Proença, F.T. Pinho // Journal of Fluids Engineering. - 2006. - Volume 128, Issue 6. P.1204-1217. https://doi.org/10.1115/1.2354524.

33. Li, A., Chen, X., Chen, L., Ga, R. Study on local drag reduction effects of wedge-shaped components in elbow and T-junction close-coupled pipes / A. Li, X. Chen, L184. DOI:. Chen, R. Gao // Building Simulation. - 2014. - 7(2). - P.175-10.1007/s12273-013-0113-z.

34. Koka, F., Myoseb, R., Hoffmannb, K.A. Numerical assessment of pulsatile flow through diverging tees with a sharp and round-edge junction / F. Koka, R. Myoseb, K.A. Hoffmannb // International Journal of Heat and Fluid Flow. - 2019. - Volume 76. - P. 1-13. DOI:10.1016/j.ijheatfluidflow.2019.01.008.

35. Kalenik, M., Chalecki, M. Wichowski, P. Real Values of Local Resistance Coefficients during Water Flow through Welded Polypropylene TJunctions / Marek Kalenik, Marek Chalecki and Piotr Wichowski // Water. 2020. - 12(3). - P. 895. DOI:10.3390/w12030895.

36. Kalenik, M. Real values of local resistance coefficient during flow of water through welded polypropylene elbows / M. Kalenik // Ochrona Srodowiska. - 2019. - Vol. 41, No. 1. - PP. 23-30.

37. Kalenik, M., Witowska, B. Research of local hydraulic resistance in PVC fittings / M. Kalenik, B. Witowska // ACTA Scientiarum Polonorium. Architectura. - 2007. - Issue 6 (3). - P.15-24. 
38. Weinerowska-Bords, K. Experimental analysis of local energy loss coefficients for selected fittings and connectors in polymeric multilayer pipe systems / K. Weinerowska-Bords // Instal. - 2014. - 6. - P.42-49.

39. Rennels, D.C., Hudson, H.M. Pipe Flow / D.C.Rennels, H.M. Hudson // A Practical and Comprehensive Guide; John Wiley Sons, Inc.:Hoboken, NJ, USA, 2012. - 320p. ISBN: 978-0-470-90102-1. 